\title{
The Effect of Polymer-Cement Stabilization on the Unconfined Compressive Strength of Liquefiable Soils
}

\author{
Ali Ateş \\ Geotechnical Division, Department of Civil Engineering, Technology Faculty, Düzce University, 81620 Düzce, Turkey \\ Correspondence should be addressed to Ali Ateş; aliates@duzce.edu.tr
}

Received 29 March 2013; Accepted 14 May 2013

Academic Editor: Osman Gencel

Copyright ( 2013 Ali Ateş. This is an open access article distributed under the Creative Commons Attribution License, which permits unrestricted use, distribution, and reproduction in any medium, provided the original work is properly cited.

\begin{abstract}
Soil stabilization has been widely used as an alternative to substitute the lack of suitable material on site. The use of nontraditional chemical stabilizers in soil improvement is growing daily. In this study a laboratory experiment was conducted to evaluate the effects of waterborne polymer on unconfined compression strength and to study the effect of cement grout on pre-venting of liquefiable sandy soils. The laboratory tests were performed including grain size of sandy soil, unit weight, ultrasonic pulse velocity, and unconfined compressive strength test. The sand and various amounts of polymer $(1 \%, 2 \%, 3 \%$, and $4 \%)$ and cement $(10 \%, 20 \%$, $30 \%$, and $40 \%$ ) were mixed with all of them into dough using mechanical kneader in laboratory conditions. Grouting experiment is performed with a cylindrical mould of $150 \times 300 \mathrm{~mm}$. The samples were subjected to unconfined compression tests to determine their strength after 7 and 14 days of curing. The results of the tests indicated that the waterborne polymer significantly improved the unconfined compression strength of sandy soils which have susceptibility of liquefaction.
\end{abstract}

\section{Introduction}

Soil stabilization refers to produce in which a special soil, a cementing material, or other chemical materials are added to the liquefiable sandy soils to improve one or more of their properties. There are two methods to enhance the properties of sandy soils, one of them is the mechanical stabilization which is mixed the natural soil and stabilizing material together for ob-taining a homogeneous mixture and the second one is adding stabilizing material into un-disturbed soils to obtain interaction by letting it permeate through soil voids $[1,2]$. Chemical stabilization is the modification of properties of a locally available soil to improve its engineering performance. The two most commonly used chemical stabilization methods are lime stabilization and cement stabilization. Additives such as fly ash and phosphogypsum can be added to the lime soil and cement soil mixtures to enhance the properties of the stabilized soil. The use of polymeric materials in setting soil improvement is growing daily. Unfortunately, little research has been completed to distinguish between products that deliver enhanced performance and those that do not. The nature of soil stabilization dictates that products may provide soil-specific properties and/or provide compatibility with environment. In other words, some products may work well in specific soil types in a given environment but perform poorly when applied to dissimilar materials in a different environment. Application of stabilizing agent on soils has a long history [3]. Cement was first used as stabilizing agent at the beginning of the 20th century to mix with the soils and form road material in the United States. Since then many other materials such as lime $[4,5]$, organic polymers [6], and their mixtures [7] have been used as stabilizing agents. Also several researchers [8-10] have discussed aqueous polymer applications while others [11-13] have provided useful data on polymer-soil interactions that determine the effectiveness of polymer solution in various applications. The objective of this research is to evaluate the effect of waterborne polymer and cement on unconfined compressive strength of liquefiable sandy soils.

\section{Materials}

2.1. The Properties of Cement. The cement used for the study is Portland cement labelled CEMI 42.5 R and the properties of which are given in Table 1. 
TABle 1: Properties of the cement.

\begin{tabular}{lc}
\hline Properties & Values \\
\hline Grade & $42.5 \mathrm{R}$ \\
Specific gravity & 3.17 \\
Fitness (\%) & 3750 \\
Consistency (\%) & 1.3 \\
Initial and final setting time (min) & $200-260$ \\
\hline
\end{tabular}

TABLE 2: Important physicochemical properties of as-received emulsion.

\begin{tabular}{lc}
\hline Name & Vinyl Acrylic-Copolymer watered solution \\
\hline Physical state & Liquid-white colour \\
Solvability in water & Solution \\
Boiling point & $100^{\circ}$ \\
Viscosity & 280 \\
Sparkling point & Over 600 \\
Non-self-burning & Nonexplosive \\
Temperature & Over 3200 \\
Density $\left(\mathrm{g} / \mathrm{cm}^{3}\right)$ & $1.11\left(20^{\circ}\right)$ \\
PH & $4-7.5$ \\
\hline
\end{tabular}

2.2. Epoxy Resin. A commercial product of epoxy resin was used, which is an emulsion synthetic elastic chemical substance that increases the bound with the substrate as additive in optimum moisture, as well as the cohesion and the strength. A multi component resin grout usually provides very high-tensile compression and bond strengths. Some important properties were given in Table 2.

2.3. The Properties of Soil Sample. Locally available sandy soil was utilized for this study and was obtained from source of sand in Duzce City in Turkey. It is necessary for the samples to be stabilized to lie in the interval of upper and lower borders on the sieve analysis graph determined by Union of Japanese Civil Engineers. For this purpose, the gradation of samples was prepared on the upper and lower borders of sieve analysis graph to be applied the emulsion according to the Union of Japanese Civil Engineers. The samples were sieved by the number of the $8 \mathrm{~mm}, 4.76 \mathrm{~mm}, 2 \mathrm{~mm}, 1 \mathrm{~mm}$, and $0.425 \mathrm{~mm}$ and the gradation was supplied mixing the grains remained on those sieves $[14,15]$.

The grain-size distribution of the soils was presented in Figure 1. The properties of the tested soils in term of particle size and sandy soil parameters were given in Table 3.

2.4. Laboratory Studies. This experimental work has been conducted to investigate the influence of curing time and percentage of waterborne polymer on the unconfined compression strength of sandy soils in Department of Civil Engineering, Faculty of Technology in Duzce University. Use of unconfined compressive strength for soil stabilizers is a quick and simple test and provides a convenient basis for comparison between stabilizer types.
TABLE 3: Engineering properties of sandy soils.

\begin{tabular}{lc}
\hline Property & Sample \\
\hline Specific gravity & 2.73 \\
Grain size & \\
$\quad$ Gravel $(>20 \mathrm{~mm})(\%)$ & 0 \\
Sand $(75-20 \mathrm{~mm})(\%)$ & 100 \\
Max. void ratio $\left(e_{\max }\right)$ & 0.77 \\
Min. void ratio $\left(e_{\min }\right)$ & 0.45 \\
Relative density, $D_{r}(\%)$ & 45 \\
Void ratio, $e(\%)$ & 1.024 \\
Optimum moisture content $(\%)$ & 13 \\
Maximum dry unit weight $\left(\mathrm{g} / \mathrm{cm}^{3}\right)$ & 1.92 \\
Soil classification $($ USCS $)$ & $\mathrm{S}$ \\
\hline
\end{tabular}

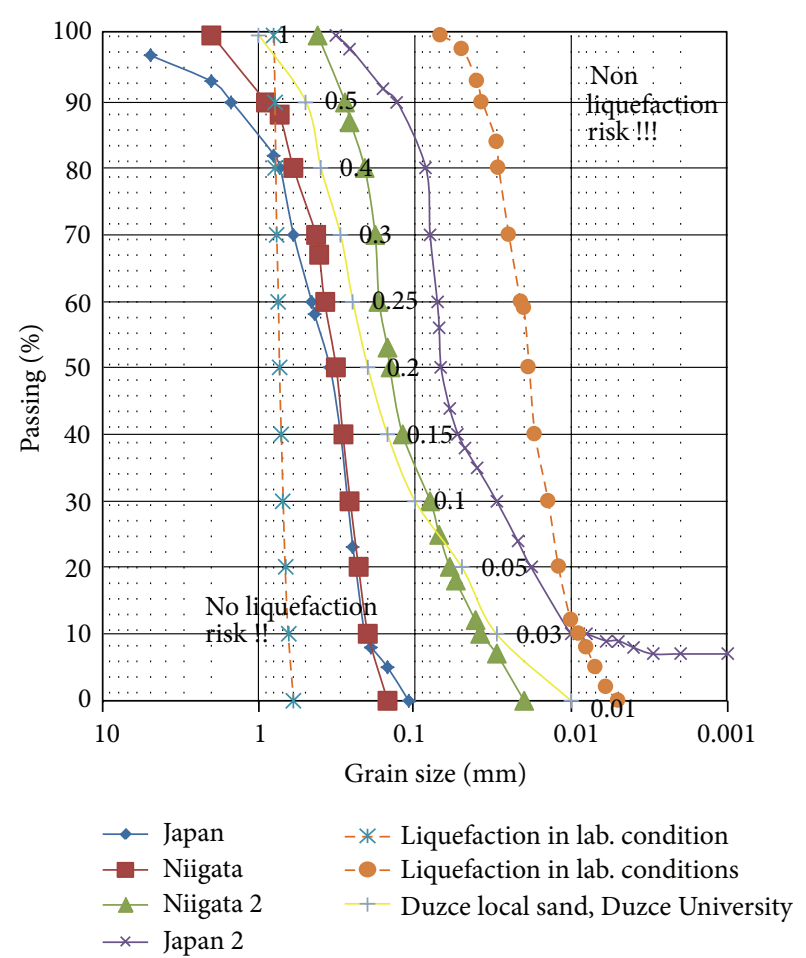

FIGURE 1: Grain size distribution of sandy soils.

Sandy soils with a different rate of cement mixing were used and various percentages of waterborne polymers were added to soils to investigate the ultrasonic pulse velocity, unit weight, and compressive strength of stabilized samples. The soils were dried before using in the mixtures. First, the required amounts of polymer as a percentage of dry weight of sample and cement were blended and then added to dry soils. The amount of aqueous polymer was chosen as 1,2 , 3 , and $4 \%$ by total weight of dry sample and the amount of cement was chosen as 10,20,30,40\% by weight of dry sample, respectively. The mixing sample was placed into the mould. After 24 hours later, the specimens were taken out of the moulds and specimens were stored in the curing room at the temperature ranging from 21 to 25 centigrade and then tested at 7 and 14 days. 


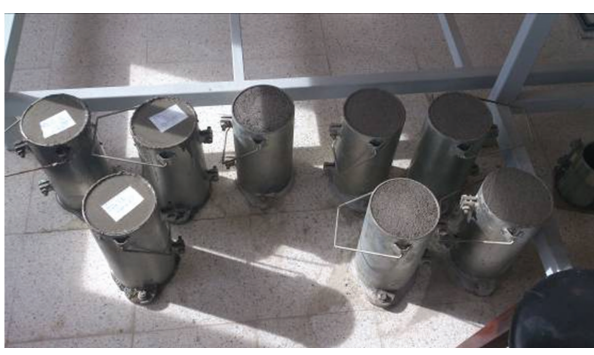

(a)

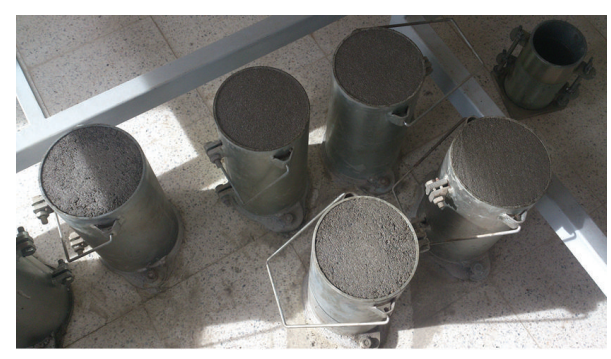

(b)

FIGURE 2: Viev of preparing the specimens in laboratory.

2.4.1. Preparation of the Samples. The preparation of the soil sample is of great importance for laboratory research. Because of using polymer which was insoluble in water, in all experiments, sands were owned dried for $24 \mathrm{hrs}$ to eliminate sand's moisture and then specified amount of polymer added to the dry cement-sand. After completing this treatment, the specimens were prepared by mixing the polymer with sand in the loose dry density of $19 \mathrm{kN} / \mathrm{m}^{3}$. The polymer mixture was developed in to dough using mechanical kneader. The uniformly mixed dough was subsequently placed into a steel mold measuring $150 \mathrm{~mm}$ in height and $300 \mathrm{~mm}$ in diameter (Figure 2). Finally, the molded specimens were left to cure at room's temperature. Specimens containing 1, 2, 3, and 4 wt.\% (\% by dry weight) polymer and 10, 20, 30, and 40 wt.\% (\% by dry weight) cement were prepared using this method. Other sets of samples were prepared using the same method and submerged in water to be cured for 7 and 14 days. In the following stage, the moisture content of the sandy soil was determined.

2.5. Curing Time. Curing times of 7 and 14 days were used in this research. Three samples for each curing time were prepared in order to provide an indication of reproducibility as well as to provide sufficient data for accurate interpolation of the results.

2.6. Submerge of Specimens in Water. In this study, each specimen was arranged vertically in a steel mould and submerged in a water tank after the specimen in each steel mould was allowed to be cured under room temperature. The specimens submerged in water for 7 and 14 days and then taken out from the water and tested within $24 \mathrm{hrs}$ of removal from the soaking reservoir, and their unconfined compressive strength was recorded. Thus, the effect of curing period on compressive strength, unit weight, and ultrasonic pulse velocity of stabilized samples was evaluated.

2.7. Unconfined Compressive Strength Testing. Unconfined compressive strength testing was performed on all extracted specimens with a constant stress rate by manually controlled test machine (Figure 3). A data acquisition system was used to record the applied load. Each specimen was loaded until peak load was obtained.

2.8. Ultrasonic Pulse Velocity Testing. The ultrasonic pulse velocity (UPV) measuring devices can be applied for the complex investigation of the soil properties (density, porosity, and strength, as well as its integrity). However, in many investigations up to now, there have been frequent references on the effect of soil stabilization close to the tested product soil cement mixing as it increases the UPV in soil. To investigate this issue more comprehensively, the specimens were made, where soil and cement with polymer of same diameter and length were assigned. The acoustic velocity wave speed of a given soil-concrete (that mixing soil is strengthened like concrete) specimen can easily be obtained with the travel time of a stress wave and the length of the specimen. The pulse is sent from the sending transducer to the receiving transducer through the soil concrete specimen as seen in Figure 4. The relationship of a specimen's acoustic velocity is simply calculated from a time and a length measurement. It should be noted that cracks, flaws, voids, and other anomalies within a material specimen could increase time of travel therefore decreasing the materials acoustic velocity. However, assuming the specimen in Figure 4 is free of anomalies, its acoustic velocity can be calculated simply by sending the pulse. The length of the specimen is $300 \mathrm{~mm}$. Figure 4 shows typical ultrasonic pulse velocity test procedure.

\section{Test Results}

For this research, it was desired to evaluate the effectiveness of the soils mixed with stabilizer at dry and wet conditions being cured after 7 and 14 days. Low to high dosage rates were used for soils at dry and wet conditions. The stabilizer dosage rates used for this study were $1,2,3$, and $4 \%$ as polymers and 10, 20, 30 , and $40 \%$ as cement.

3.1. Effect of Curing Time on Strength. The results of curing times on unconfined compression strength results were shown in Figures 5 and 6 . The unconfined compression strength of stabilized samples increases with curing time. Both specimens containing polymer content of $1-4 \%$ by wt. $\%$ and cement content of 10-40 wt.\% were cured in air and water during 7 and 14 days. So, by increasing the polymer contents, cross-linking between polymer network increased and the strength of soil increased. The strength of the specimens containing 3\% polymer and 30\% cement content at 7 days of curing time achieved $90 \%$ of the 14 days compressive strength. It is clear from Figures 5 and 6 that compressive strength of the stabilized soils was increased while increasing 


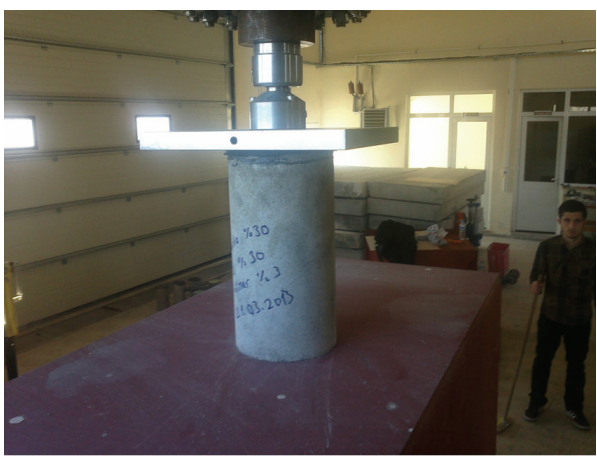

(a)

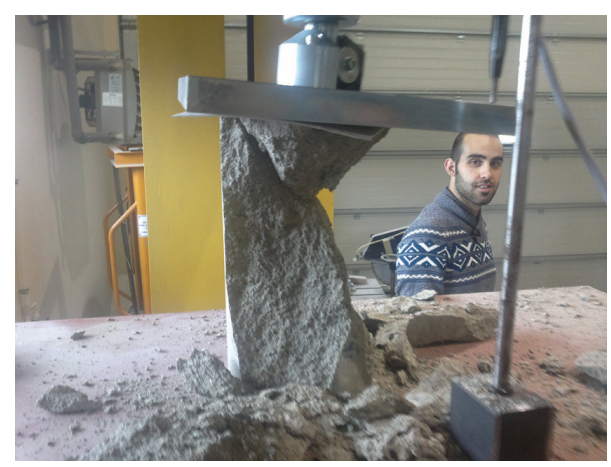

(b)

FIGURE 3: Arrangement of specimen for compressive test in lab.

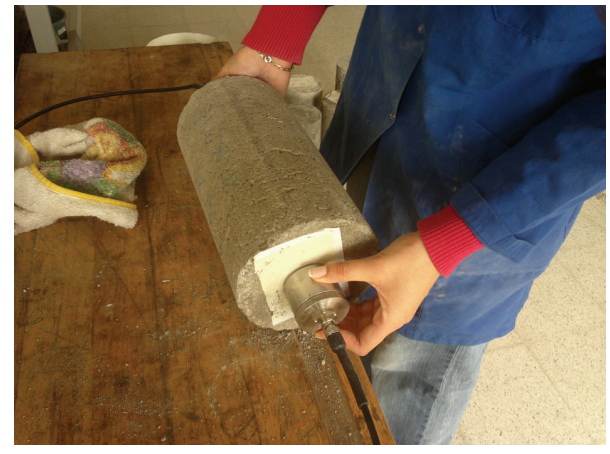

FIGURE 4: Ultrasonic pulse velocity measurement.

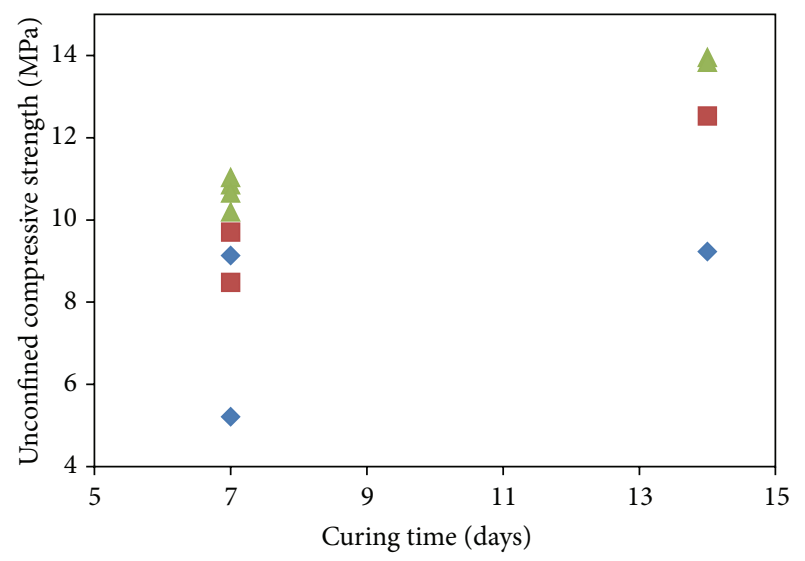

- Sand $+20 \%$ cement

- Sand $+30 \%$ cement

$\triangle$ Sand $+40 \%$ cement

Figure 5: The unconfined compressive strength for specimens in water.

the curing time in both water and air curing conditions. As it is expected the effect of water curing on strength is more effective than air curing.

3.2. Effect of Curing Condition on Strength. Effects of wet conditions on unconfined compression strength stabilized soils containing polymer and cement were presented in Figure 5.

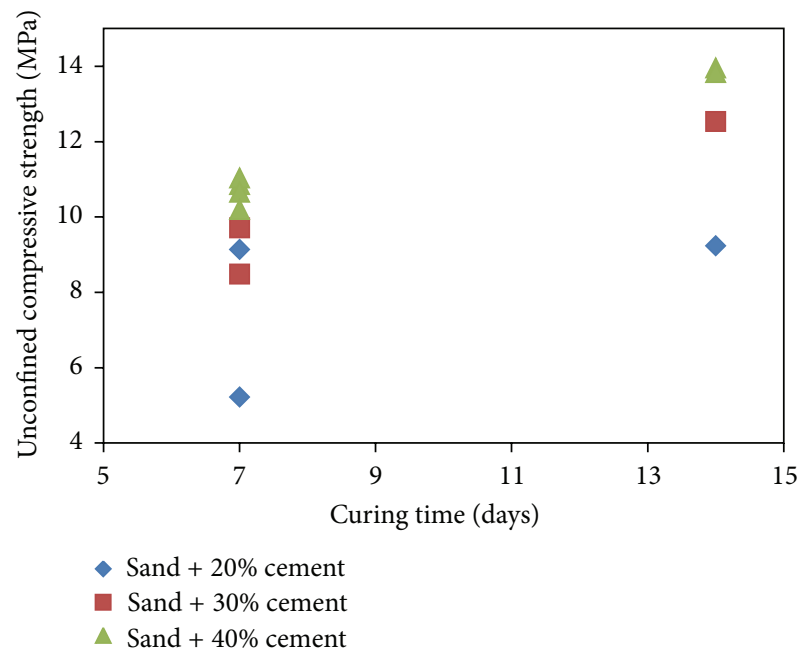

FIGURE 6: The unconfined compressive strength for specimens in air.

As discussed earlier in this paper, the treated samples were tested using dry and wet curing conditions to provide an indication of the material's moisture content. After 7-day curing period, placing the specimens in water tank provided an excellent indicator of the material's strength under wet conditions. Strength properties of the specimens that consist of 20-40 wt. \% cement and $2-4 \%$ polymer content increased after submerging in water relatively. The reason of increasing the unconfined compressive strength of specimens is based on the role of water as catalyst.

3.3. Effect of Cement and Polymer Content on Strength. The results of unconfined compressive strength on stabilized soils with 10-40 wt.\% cement and 1-4 wt.\% polymer were presented in Figure 7. Stabilized soils with the $1 \%$ polymer have lower strength than 2, 3, and $4 \%$ polymer and could not record the value of unconfined compressive strength in this study. For each specimen, the unconfined compression strength increases with increment cement and polymer content. This means that the sandy soil becomes hardened with an increase in the cement content. This phenomenon 


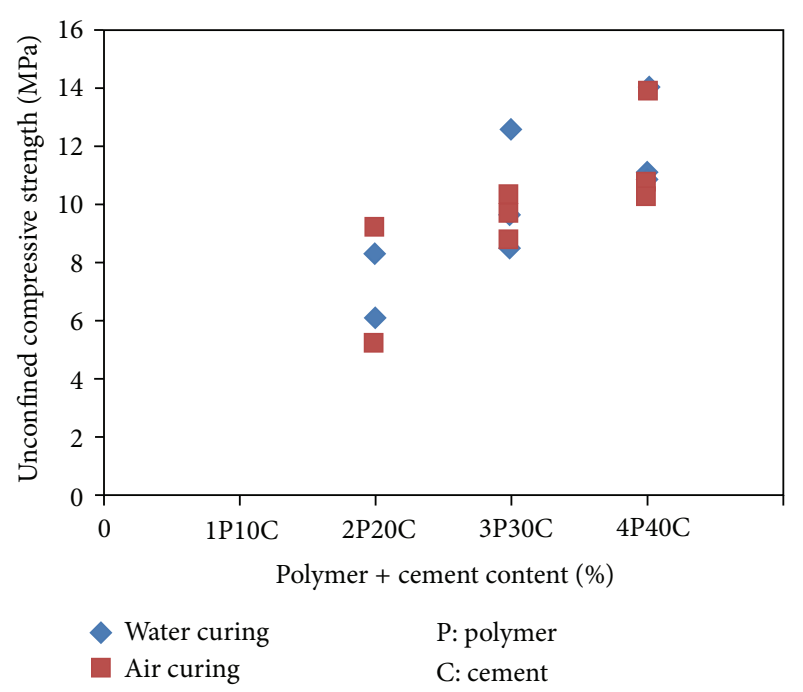

FIGURE 7: Unconfined compressive strength of soils modified with cement and polymer.

is explained by the fact that the fine grains of cement are positioned around and among the sand grains; the polymer covered all of sample's area.

The unconfined compressive strength increased linearly with a polymer concentration up to $4 \mathrm{wt}$.\% for all of the sandy soil used. Comparing the performance of the emulsion in improving the unconfined compressive strength, it could be seen that the unconfined compression strength increases with increment polymer content. This phenomenon is explained by the fact that an increment in polymer content resulted in enhancing bond mechanisms of the sand-emulsion interface. It could be seen that specimens consist of $4 \mathrm{wt} . \%$ polymer gave the highest value for all specimens and specimens consist of $1 \mathrm{wt} . \%$ polymer gave the lowest values that furthermore the values could not be recorded for polymer at a rate of $1 \%$ successively. The unconfined compressive strength value of sand at 2 and $4 \mathrm{wt}$.\% polymer content was 5.21 and $13.83 \mathrm{MPa}$, respectively, which are more than $100 \%$ increased.

The results obtained in the simple compression tests at 7 days have shown an increase in the strength of the stabilized material against the natural material whose strength was $10.65 \mathrm{MPa}$. The increases in strength obtained were proportional to the amount of polymer added, except for combination of $1 \%$ which reached $5.12 \mathrm{MPa}$, only achieved by the combination of $2-4 \%$. This has been interpreted as a result of the combination of the effect of the polymer matrix, not modified by low addition of polymer (at a rate of polymer $1 \%$ ), and, on the other hand, the binding effect of the polymer. For content of $2 \%$ and upwards may modify the cement matrix. Therefore the increased strength was due only to the polymer. The results after 14 days showed values between 10.19 and 10.25 MPa in all combinations except that of $1 \%$, which approximately reached $0.35 \mathrm{MPa}$. Even more, it was so weak that the result could not be recorded. The value of $10.65 \mathrm{Mpa}$ was obtained in the combination of $3 \%$ and $4 \%$ polymer and the highest was obtained in the whole experiment. The values after 14 days, the results were very similar at those of 7 days,

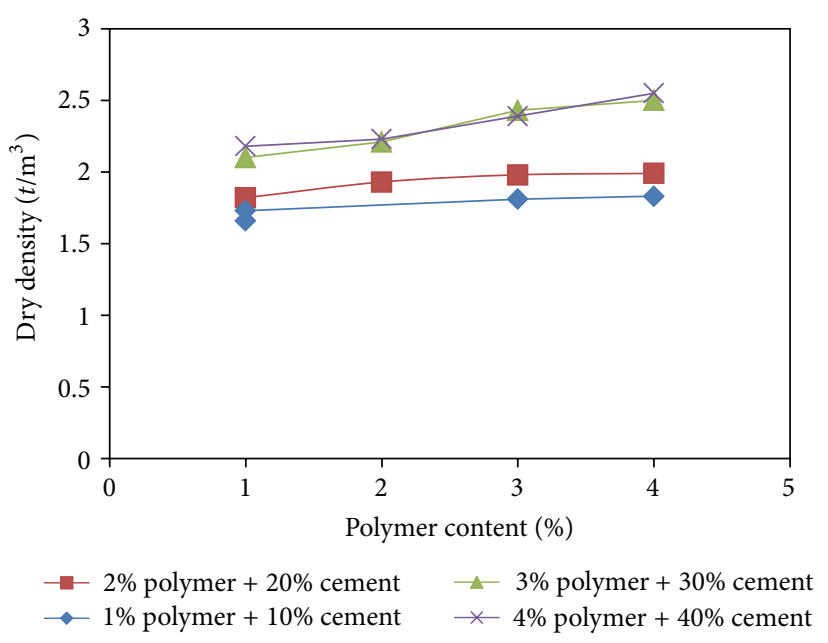

FIGURE 8: Effect of polymer content on maximum dry density of soil in dry conditions for 7 days.

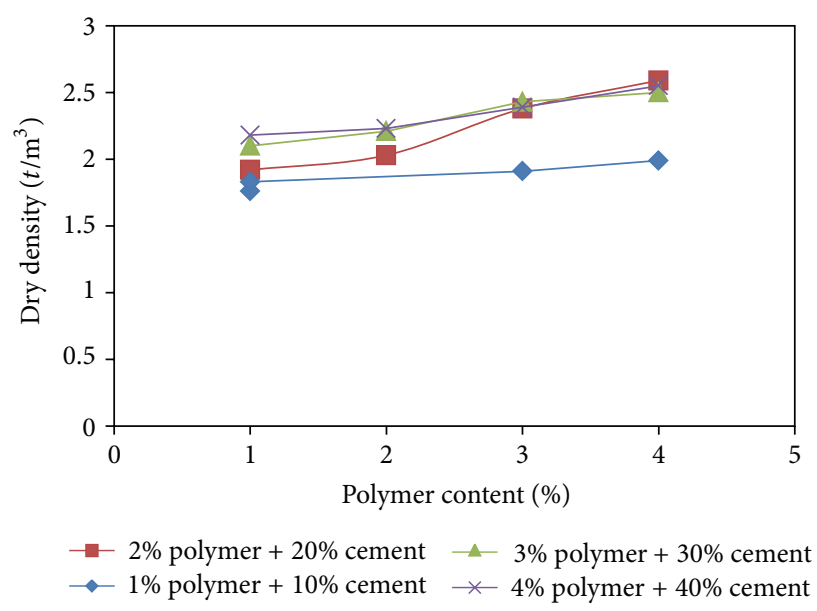

FIGURE 9: Effect of polymer content on maximum dry density of soil in wet conditions for 7 days.

reaching between 5.21-6.12 MPa except for the combination of $1 \%$. For this curing time the greatest strength was obtained for the combination of $4 \%$, with $10.65 \mathrm{MPa}$, a value very close to those obtained with combination of $3 \%$, with $9.74 \mathrm{MPa}$. The analysis of test results of unconfined compression shows that the addition of $1 \%$ of polymer is insufficient since, while it changes the polymer nature of the soil, it is not enough for the formation of chemical reactions over the curing time. On the other hand, the combination of $4 \%$ clearly shows the excess values of polymer in the soil. The combination which improved optimal point from the standpoint of improving the resistant properties of soil tested against the addition of polymer was $4 \%$ and a compressive strength of $10.65 \mathrm{MPa}$.

\subsection{Effect of Polymer Content on Maximum Dry Density.} The effect of polymer content on maximum dry and specific density was presented in Figures 8, 9, 10, and 11. For any particular amount of polymer, an increase in polymer content 


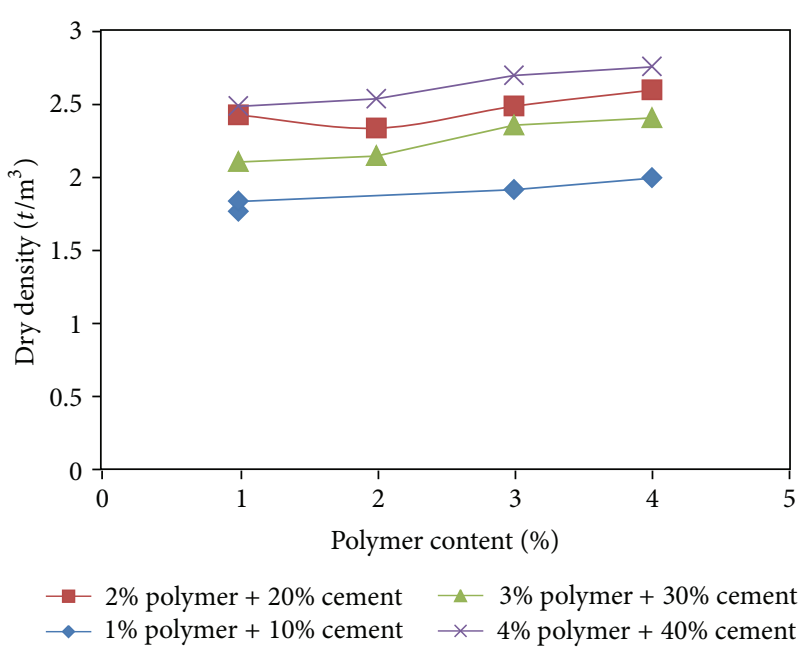

FIGURE 10: Effect of polymer content on maximum dry density of soil in dry conditions for 15 days.

causes an increment in dry density. As already explained, this is due to increment of average unit weight of solids in the sandy soil polymer mixture. It is observed from the Figures $8,9,10$, and 11 that the plot of variation of dry density with respect to polymer content is more or less proportional in shape.

3.5. Effect of Polymer Content on Optimum Moisture Content. Optimum moisture content (OMC) is increased with increase in polymer content. The maximum OMC is recorded $13.8 \%$ for $4 \%$ polymer content, and as low as 5.4 for soil with $1 \%$ of polymer content. The initial inclusion of content of $1 \%$ caused a more sudden hike in the OMC than that of the ordinary sandy soil, and a further increase in polymer content increased the OMC. But in all cases, the OMC is greater than that of raw sandy soil. The effect of polymer content on OMC was presented in Figures 12, 13, 14, and 15.

3.6. Ultrasonic Pulse Velocity Test Results. The velocity versus density that results in pulse passing through in soil cement with polymer mixing was presented in Figures 16, 17, 18, and 19.

An increase in polymer content causes increment in velocity of soundings. This is due to increment of average unit weight of solids in the soil cement polymer mixture. It was observed from Figures 16, 17, 18, and 19 that the plot of variation of velocity versus density with respect to polymer content is more or less proportional.

\section{Conclusions}

This study was undertaken to investigate the influence of polymer percentage, curing time, and dry and wet conditions on the unconfined compressive strength of stabilized cement with sandy liquefiable soils. The results of the study were presented in following conclusions.

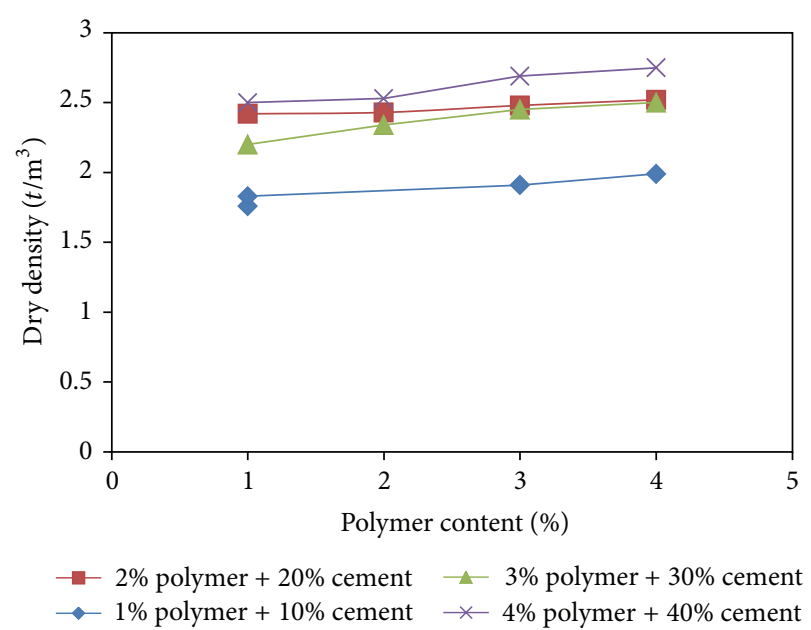

FIGURE 11: Effect of polymer content on maximum dry density of soil in wet conditions for 15 days.

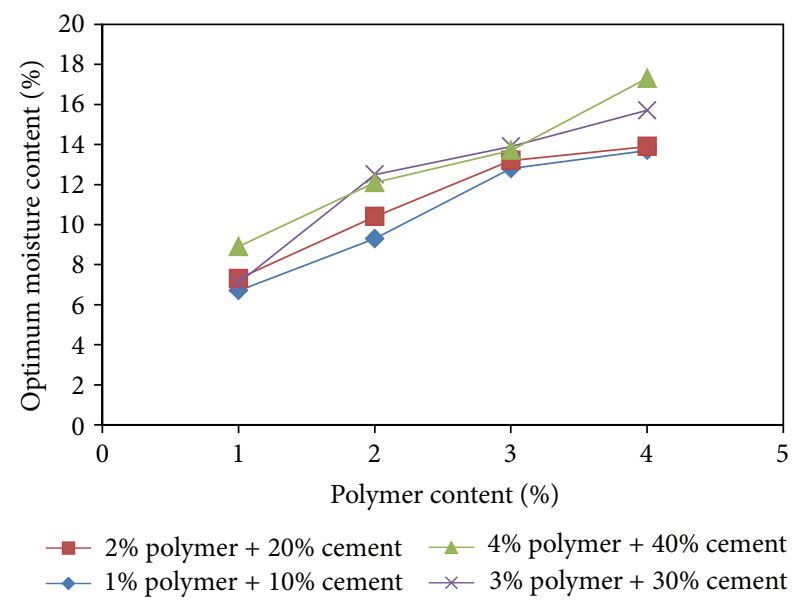

FIGURE 12: Effect of polymer content on OMC in dry conditions for 7 days.

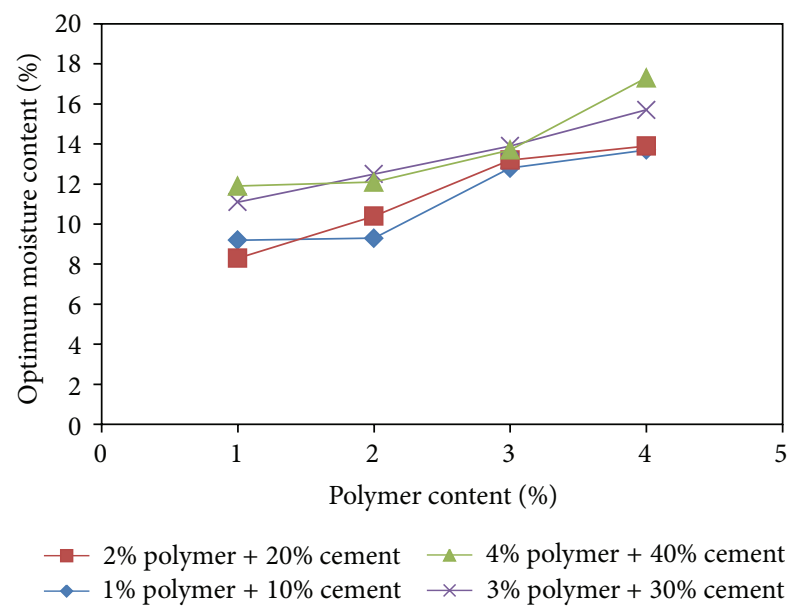

FIGURE 13: Effect of polymer content on OMC in wet conditions for 7 days. 


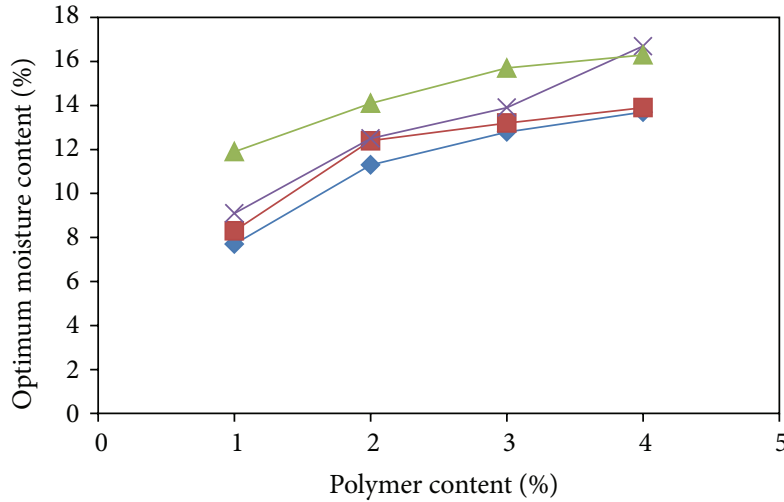

$-2 \%$ polymer $+20 \%$ cement $\rightarrow 4 \%$ polymer $+40 \%$ cement $\leftarrow 1 \%$ polymer $+10 \%$ cement $\rightarrow 3 \%$ polymer $+30 \%$ cement

FIGURE 14: Effect of polymer content on OMC in dry conditions for 15 days.

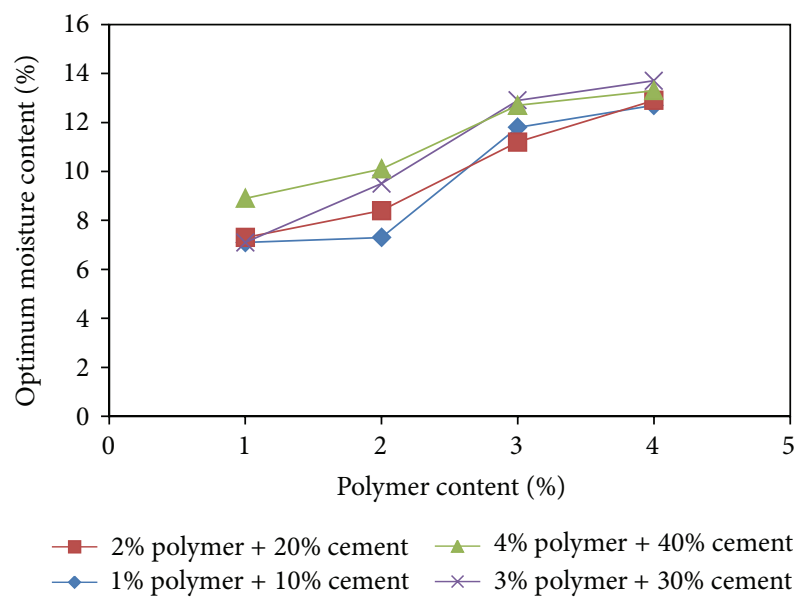

Figure 15: Effect of polymer content on OMC in wet conditions for 15 days.

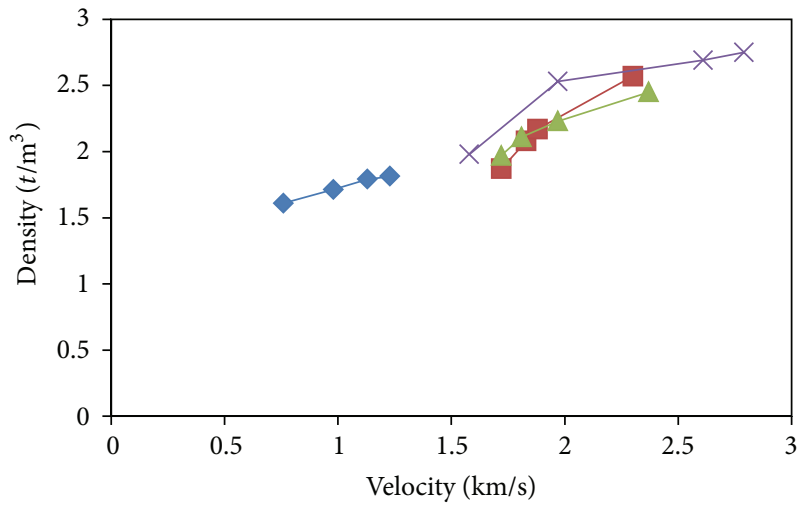

- $2 \%$ polymer $+20 \%$ cement $\rightarrow 3 \%$ polymer $+30 \%$ cement $\rightarrow 1 \%$ polymer $+10 \%$ cement $\rightarrow 4 \%$ polymer $+40 \%$ cement

FIGURE 16: Ultrasonic pulse velocity test procedure in dry conditions for 7 days.

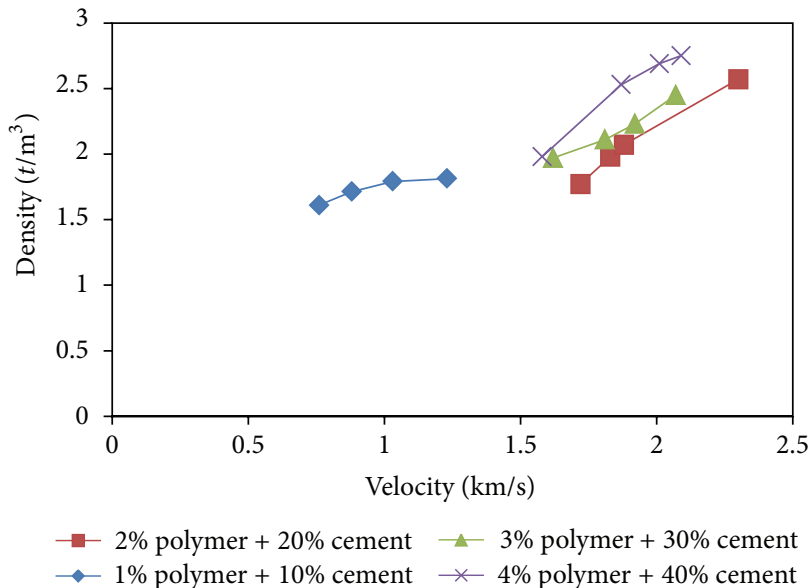

FIGURE 17: Ultrasonic pulse velocity test procedure in wet conditions for 7 days.

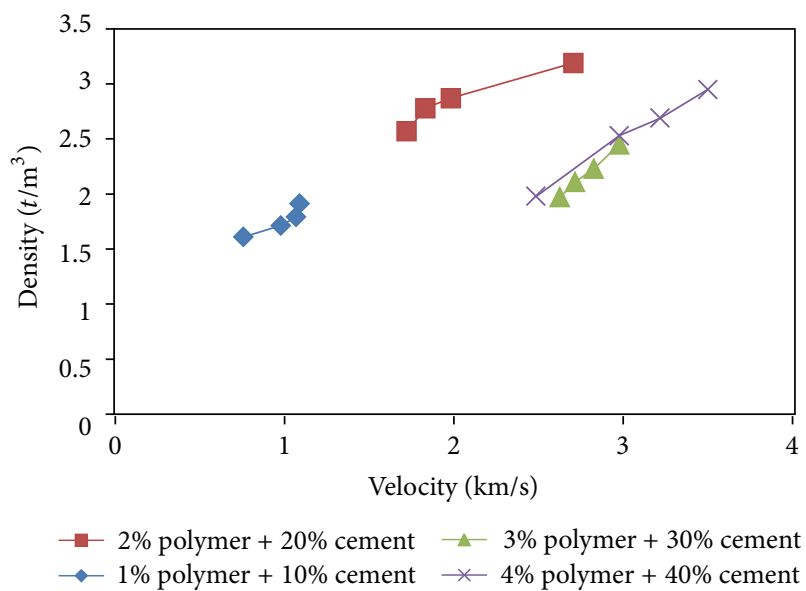

FIGURE 18: Ultrasonic pulse velocity test procedure in dry conditions for 14 days.

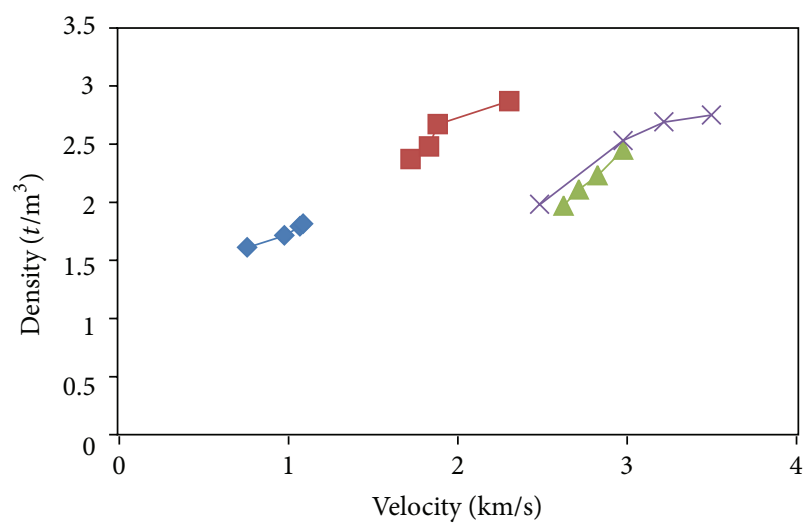

- $2 \%$ polymer $+20 \%$ cement $\rightarrow 3 \%$ polymer $+30 \%$ cement $\rightarrow 1 \%$ polymer $+10 \%$ cement $\rightarrow 4 \%$ polymer $+40 \%$ cement

FIGURE 19: Ultrasonic pulse velocity test procedure in wet conditions for 14 days. 
(i) When the soil has stabilized with polymer, it increases the dry density of the soil due to specific gravity and unit weight of polymer. The variation is linear for both cases. Initial introduction of polymer content in to the soil causes an increase in OMC, so further increase in polymer content may cause to enhance in OMC.

(ii) The addition of polymer to the natural soil produced an improvement in its mechanical capacities that were determined by unconfined compression tests, from the first period of curing examination. From the strength aspect of liquefiable sandy soils, the optimum polymer content estimated polymer at 3\%, since in all tests it yielded the best result with the rate of $3 \%$ dosage of polymer.

(iii) The strength of sandy soil mixtures has increased with increment of cement contents up to about $30 \%$ and above $30 \%$ cement content; the strength of the soil almost becomes constant. This phenomenon is explained by the fact that the fine grains of cement were covered and positioned around and among the sand grains.

(iv) The unconfined compressive strength of specimens has increased with increment of polymer contents; this phenomenon is explained by the fact that increment of polymer and the polymer cover all of sample's area and increases cross-links.

(v) For specimens submerging in water, there are two types of results. First one is about specimensens that consist of 30 and $40 \mathrm{wt} . \%$ cement content at $4 \%$ polymer and 20 and $30 \mathrm{wt} . \%$ cement content at 3\% polymer; the strength properties of these specimens were reduced after submerging in water. Second is about the rest of specimens. After 7 days of submerging, the unconfined compressive strength of the specimens increased while it was less than the dry condition. The reason of increasing the unconfined compressive strength of specimens is the role of water as catalyst. When specimens submerged in water, the $\mathrm{H}^{+}$ions of water react with three-member epoxies' rings and the epoxies' ring was opened, then the hardener easily can react with resin. So, the strength of specimens increased.

(vi) The unconfined compressive strength significantly increased with curing time. The unconfined compressive strength of the mixtures rapidly increased at 7 days.

(vii) The maximum unconfined compressive strength values have increased with increase of the polymer content. Sandy soils stabilized with 3, 4\% polymer at $30,40 \%$ cement content have higher values on unconfined compressive strength than other percentages.
[2] B. K. G. Theng, "Clay-polymer interactions: summary and perspectives," Clay and Clay Minerals, vol. 30, no. 1, pp. 1-10, 1982.

[3] K. E. Clare and A. E. Cruchly, "Laboratory experiments in the stabilization of clays with hydrated lime," Geotechnique, vol. 7, pp. 97-110, 1957.

[4] B. K. G. Theng, "Clay-polymer interactions: summary and perspectives," Clay and Clay Minerals, vol. 30, no. 1, pp. 1-10, 1982.

[5] D. Dermatas and X. G. Meng, "Utilization of fly ash for stabilization/solidification of heavy metal contaminated soils," Engineering Geology, vol. 70, no. 3-4, pp. 377-394, 2003.

[6] S. M. Lahalih and N. Ahmed, "Effect of new soil stabilizers on the compressive strength of dune sand," Construction and Building Materials, vol. 12, no. 6-7, pp. 321-328, 1998.

[7] B. Indraratna, "Utilization of lime, slag and fly ash for improvement of a colluvial soil in New South Wales, Australia," Geotechnical and Geological Engineering, vol. 14, no. 3, pp. 169191, 1996.

[8] V. S. Green, D. E. Stott, L. D. Norton, and J. G. Graveel, "Polyacrylamide molecular weight and charge effects on infiltration under simulated rainfall," Soil Science Society of America Journal, vol. 64, no. 5, pp. 1786-1791, 2000.

[9] A. B. Moustafa, A. R. Bazara, and A. R. Nour El Din, "Soil stabilization by polymeric materials," Angenandte MaKromoleKular Chemie, vol. 97, no. 1, pp. 1-12, 2003.

[10] S. A. Naeini and A. Mahdavi, Effact of polymer on shear strength of silty sand [M.S. thesis], Civil Engineering Department, Imam Khomeini International University, Qazvin, Iran, 2009.

[11] J. L. Daniels, H. I. Inyang, and I. K. Iskandar, "Durability of Boston Blue Clay in waste containment applications," Journal of Materials in Civil Engineering, vol. 15, no. 2, pp. 144-152, 2003.

[12] J. L. Daniels and H. I. Inyang, "Contaminant barrier material textural response to interaction with aqueous polymers," Journal of Materials in Civil Engineering, vol. 16, no. 3, pp. 265-275, 2004.

[13] S. A. Naeini and M. Ghorbanalizadeh, "Effect of wet and dry conditions on strength of silty sand soils stabilized with epoxy resin polymer," Journal of Applied Sciences, vol. 10, no. 22, pp. 2839-2846, 2010.

[14] ASTM, "Standard practice for classification of soils for engineering purposes (Unified Soil Classification System)," ASTM D2487, ASTM, West Conshohocken, Pa, USA, 2000, http://www.astm.org/Standards/D2487.htm.

[15] H. Tsuchida, "Prediction and countermeasure against liquefaction in sand deposits," in Proceedings of the Seminar of the Port and Harbour Research Institute, vol. 3, pp. 1-3, Ministry of Transport, Yokosuka, Japan, 1970.

\section{References}

[1] W. H. Perloff, Soil Mechanics, Principal and Applications, John Wiley \& Sons, New York, NY, USA, 1976. 

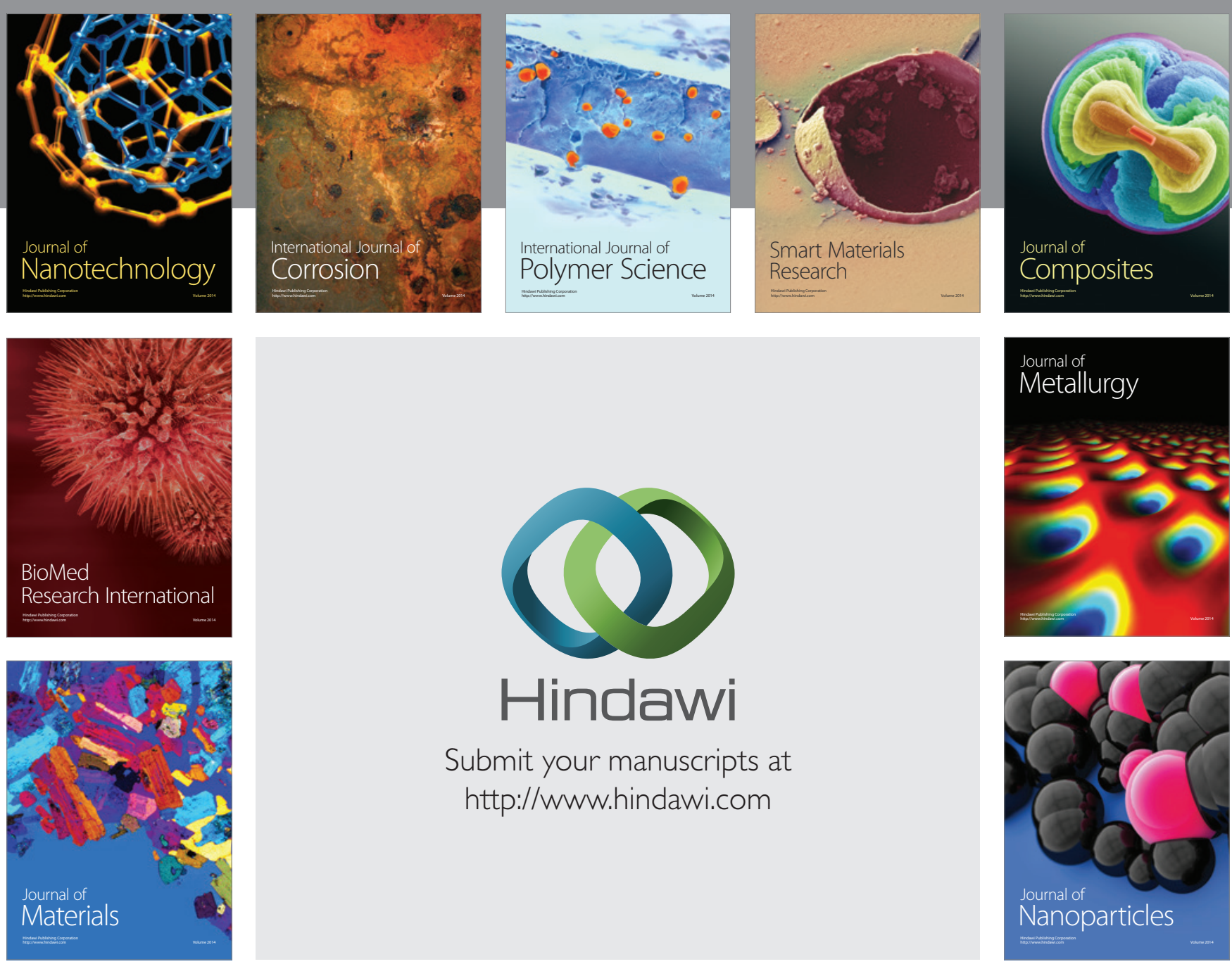

Submit your manuscripts at http://www.hindawi.com
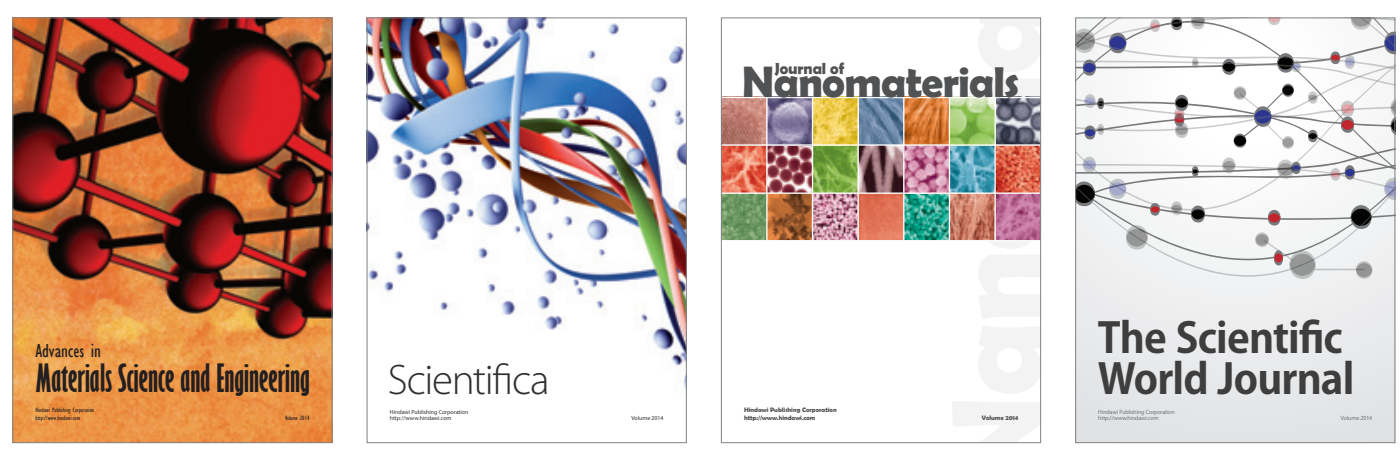

\section{The Scientific World Journal}
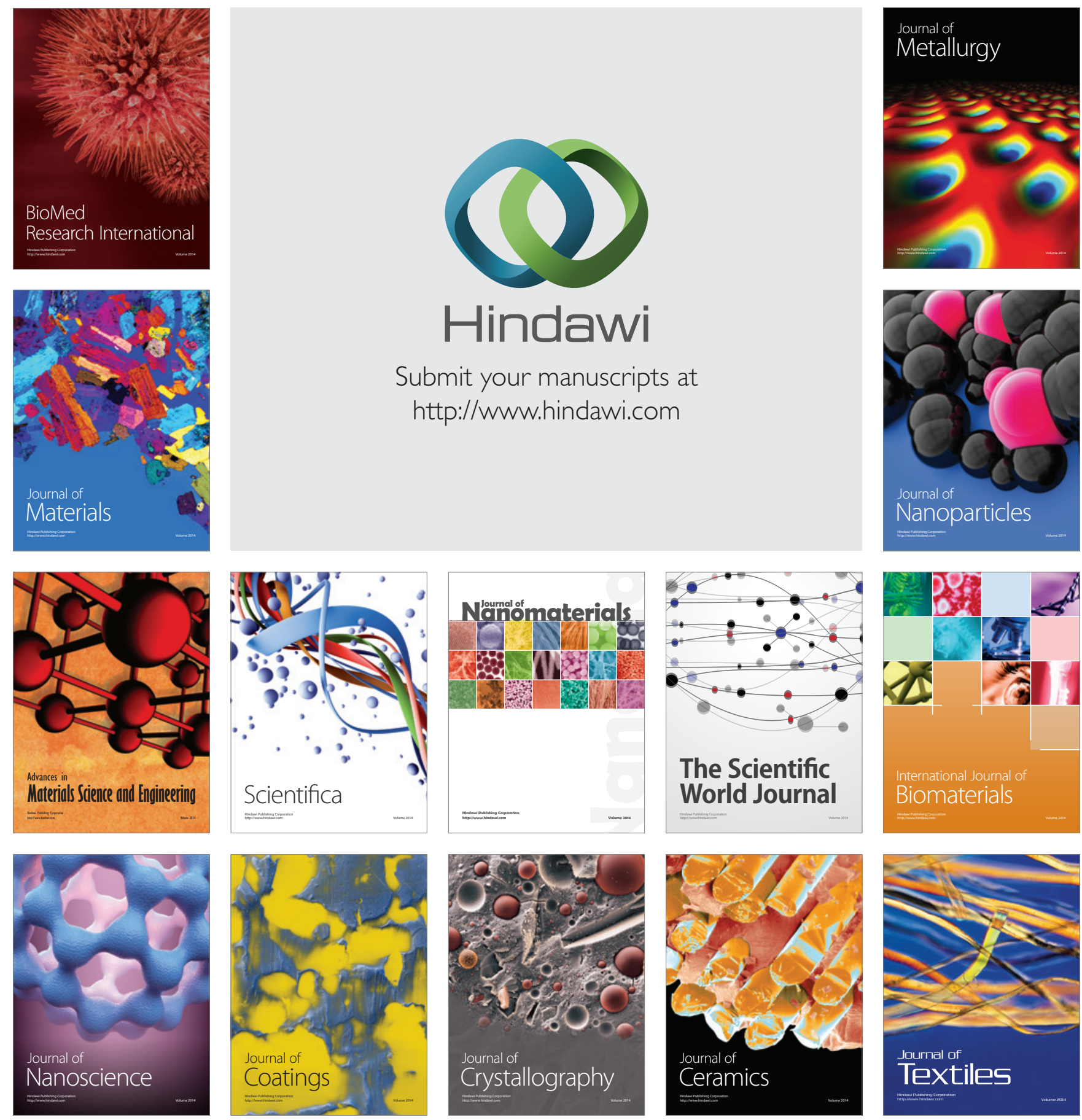